Vice-President, Dr. D. L. Gunn; President-Elect, Sir Vincent Wigglesworth; Treasurer, Dr. F. Raw; General Secretary, Dr. F. T. Last; Programme Secretary, F. G. H. Lupton; Editor, R. W. Marsh; Assistant Editor, F. H. Jacob. New members of Council elected were: Dr. P. M. Cartwright, J. M. Holborn, Dr. A. F. Murant and Dr. A. G. Walker.

\section{Course in Quantum Electronics}

AN advanced course in "Quantum Electronics", leading to a diploma or M.Sc., will be held at the University of Southampton, commencing in October 1965. The aim of the course is to provide an understanding of the basic principles and operation of modern electronic devices, particularly masers and lasers and their applications in the fields of communications, engineering, science and technology. The Department of Electronics, which is sponsoring the course, is engaged on a programme of research on solid-state devices, gas discharges, electron-spin resonance and lasers, and is therefore well equipped for the course. University graduates with suitable science or engineering degrees, or those with equivalent qualifications, are eligible to apply for entry to the course, which will consist of lectures, seminars and laboratory work including an individual project of a research nature. The lectures will extend over the three terms of the university session and a written examination will be held at the end of the session. On successful completion of the examination and the project, the student will become eligible for the award of a Diploma of the University of Southampton. Students recognized by the University for entry to a higher degree course and who pass the examination at a high standard may then proceed with a special project for an additional three months and submit a dissertation for the award of an M.Sc. degree. Application for entry to the course should be made, before June 30, to the Academic Registrar, University of Southampton.

\section{Endeavour Prizes}

Prizes totalling 100 guineas are offered by Imperial Chemical Industries Ltd., publishers of the international scientific review Endeavour, for essays submitted on scientific subjects. In addition to the cash prizes, the prizewinners will receive invitations to attend the whole of the British Association meeting at Cambridge during September 1-3. Accommodation will be provided in Cambridge, and travelling expenses within the United Kingdom will be paid. As the primary purpose of these awards is to stimulate younger scientists to take an interest in the work of the British Association and to raise the literary standard of scientific writing, the competition is restricted to those whose twenty-fifth birthday falls on or after September 1, 1965. Five prizes will be awarded, namely: a first prize of 50 guineas; a second prize of 25 guineas; a third prize of 15 guineas; two special prizes of 5 guineas each for competitors who have not passed their eighteenth birthday on September 1, 1965. The subjects for the essays are as follows: (1) physics of the Moon; (2) physiological basis of memory; (3) molecular sieves; (4) chemicals from oil; (5) mechanisms of enzyme action; (6) strength of materials. The essays, which must be in English and typewritten, should not exceed 4,000 words in length, and only one entry is permitted from each competitor. All entries should be addressed to: the Deputy Secretary, British Association for the Advancement of Science, 3 Sanctuary Buildings, Great Smith Street, London, S.W.1, and the envelope should be clearly marked 'Endeavour Prize Essay'. The latest date for receipt of entries is June 1, 1965. The essays must be submitted without signature, and the competitor's full name and address and date of birth should be enclosed in a sealed covering letter attached to the essay and addressed to the Deputy Secretary of the British Association.

\section{Announcements}

Prof. P. J. W. Debye, professor emeritus at Cornell University, and winner of the 1936 Nobel Prize for chemistry, has been awarded the fourth American Physical Society High-polymer Physics Prize, sponsored by the Ford Motor Company. The 1,000-dollar award was presented to Prof. Debye in recognition of his original researches on polymer structure.

Dr. A. T. MCPherson retired from his position as special assistant for international standards in the Institute for Applied Technology, U.S. National Bureau of Standards, on February 26. Dr. McPherson is distinguished for his contributions to the development and advancement of standards of practice, electrical insulation, natural and synthetic rubber and high polymers.

A CONFEREnce on "Medical Diagnostic Applications of Ultrasound", sponsored by the Postgraduate Medical Program of the University of Pittsburgh School of Medicine, will be held in Pittsburgh during May 20-21. Further information can be obtained from Dr. C. Moses, University of Pittsburgh School of Medicine, Pittsburgh, Pennsylvania.

A CONFEREnCE on "Components and Materials used in Electronic Engineering" will be held at the Institution of Electrical Engineers during May 17-20. The programme will include sessions on: resistors; capacitors and dielectrics; magnetic materials and other memory devices; components under environmental stresses and construction techniques; electromagnetic devices; some aspects of component reliability; microelectronies; semiconductor devices. Further information can be obtained from the Institution of Electrical Engineers, Savoy Place, London, W.C.2.

A symposium on "Electrical Conduction at Low Temperatures", organized by the Low Temperature and Testing Groups of the Institute of Physics and the Physical Society, will be held at the Royal Aeronautical Society, London, during May 20-21. The programme will include: electron scattering by impurities, dislocations and other lattice defects; size effects; magneto-resistance; factors determining the current carrying capacity of superconductors; alternating current losses in super-conductors. Further information can be obtained from the Administration Assistant, the Institute of Physies and the Physical Society, 47 Belgrave Square, London, S.W.1.

INTENSIVE courses of four weeks' duration will be held at the Department of Production and Industrial Administration, College of Aeronauties, Cranfield, during the 1965-66 session. The complete programme of postgraduate courses now planned includes: one- and two-year full-time residential courses, two-day management appreciation courses and four-week specialist short-duration courses. These courses are concerned with the application of instrumentation and automation to machine tools and production equipment, with particular emphasis on the need for flexibility in operation and precision in manufac. ture. Further information can be obtained from the Registrar, College of Aeronauties, Cranfield, Bedford.

As international symposium on "Autoclaved Calcium Silicate Building Products", arranged under the auspices of the Road and Building Materials Group of the Society of Chemical Industry, will be held at the School of Pharmacy, London, during May 18-21. The symposium will include sessions on: the chemical, physical and mechanical properties of the hydrous (autoclaved) calcium silicates; manufacture of calcium silicate building products; design, properties and behaviour of building structures (including industrialized unit construction) in these materials. Further information can be obtained from Mr. H. N. Le日, Welwyn Hall Research Association, Church Street, Welwyn, Herts. 